\title{
Critical Evaluation of Frontal Image-Based Gender Classification Techniques
}

\author{
Hira Khalid Khan ${ }^{1}$, Abdul Salam Shah ${ }^{2 *}$ and Muhammad Asim Khan ${ }^{3}$ \\ ${ }^{1,2}$ SZABIST, Islamabad, Pakistan \\ ${ }^{3}$ FUUAST, Islamabad, Pakistan \\ ${ }^{1}$ somefragrance6@gmail.com, ${ }^{2 *}$ shahsalamss@gmail.com, \\ ${ }^{3}$ m.asimkhattak@gmail.com
}

\begin{abstract}
The face describes the personality of humans and has adequate importance in the identification and verification process. The human face provides, information as age, gender, face expression and ethnicity. Research has been carried out in the area of face detection, identification, verification, and gender classification to correctly identify humans. The focus of this paper is on gender classification, for which various methods have been formulated based on the measurements of face features. An efficient technique of gender classification helps in accurate identification of a person as male or female and also enhances the performance of other applications like Computer-User Interface, Investigation, Monitoring, Business Profiling and Human Computer Interaction (HCI). In this paper, the most prominent gender classification techniques have been evaluated in terms of their strengths and limitations.
\end{abstract}

Keywords: Gender Classification, Face Detection, Face Images, Discrete Wavelet Transform (DWT), Human Computer Interaction (HCI), Support Vector Machine (SVM), Principal Component Analysis (PCA)

\section{Introduction}

The Gender classification is the dynamic areas of research in image processing and design recognition and presently, most of the work in this research area turns around a frontal face image based classification. Gender classification is the process to cluster male and female according to their category on the basis of identical features of the face. Humans can easily distinguish between the genders by observing the faces. The way they behave and interact with each other in the society depends on the identification of the gender they meet. For the identification and observation of the faces, humans can easily collect information such as faceexpression, feelings, and the estimation of age [1]. Humans can also identify the gender accurately although if the male or female face is scratched. The gender classification is a key problem for the machines like MRI Classification, Signature Verification and Pattern recognition problems [2-3]. The computerized gender classification is gaining much popularity because of rapid development in the fields of the internet, human-computer interaction, Introduction of an electronic system in banking and commerce, security [4-5]. Researchers have introduced different techniques of gender classification based on the pixels and other features. A picture is composed of thousands of pixels. Pixel-based techniques are slow as compared to feature-based techniques. If insufficient face features are used, then the best face feature classifier will be unable to accomplish a higher accuracy rate.

*Corresponding Author 
Geometric based face features like eyes, nose, and chin, makes the system further stable and is able to support changes of face expressions, brightness and poses [6]. The features are of two types; appearance-based and geometric-based. The methods/models focusing on apparent features such as raw pixels, Haar-like features, LBP features, have observed higher growth due to the manageability of unchecked variants. Geometrical features relate to features that depend on association such as the area, angle, distance and other measurements between features of the face [7].

Normally every model has following three stages; pre-processing, features extraction and classification as shown in Figure 1.

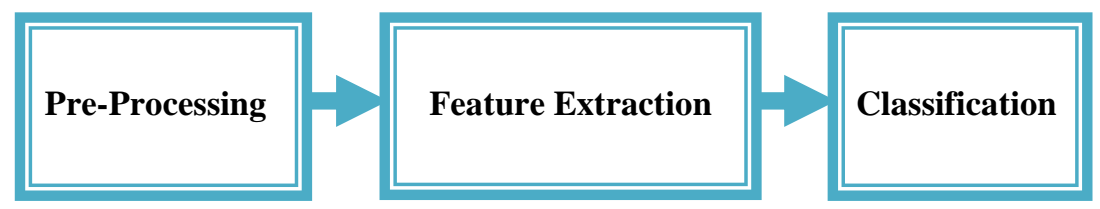

Figure 1. Gender Classification Steps

In this paper we will analyze each step of already proposed model, and identify their limitations. The structure of the remaining paper is organized as; the Literature Review is presented in Section 2, the Critical Evaluation table is provided in the Section 3, and finally the Conclusion and Future work is provided in the Section 4.

\section{Literature Review}

Dey et. al., in [8] proposed gender detection technique. In the first step identification of face area from a given input image has been carried out. The detected facial area is then classified for the gender of the face. The proposed method has four main concepts; Haar Features or Simple Rectangular face features, Important Image for quick face recognition, Adaboost algorithm for the machine learning method, and a Cascaded-Classifier for combining many characteristics efficiently. The Region of Interest (ROI) from the image is selected and passed through a Discrete Cosine Transformation (DCT) that subdivides the entire image into sub-regions. The area outside of the ROI removed by applying the noise filter. The histogram equalization has been used to adjust the gray scales of the image. The Local Binary Pattern (LBP) has been used for feature extraction. The images have been passed through the Discrete Cosine Transformation (DCT) module, for the compression of the images and representation of an image having different magnitudes and frequencies. They have used Gender Detection Classifier, to store available examples and classify images based on a similarity measure. The decision of classification is based on the hit score. The accuracy of the system is less than $70 \%$ without histogram equalization which increases up to $80 \%$ after applying histogram equalization. This system does not work correctly with images which are not in front sight also the angle faces decrease the performance. The system takes less time for the detection of gender from face images. The overall accuracy of the system is $78.91 \%$.

Khan et. al., in [9] proposed a three stages method for grouping genders into male and female. For the Feature Extraction authors have used geometrical measurements. During the Classification Weka J48 classifier has been used for training data set and generating rule set. Finally, to confirm the accuracy of classified rule set Validation has been used. For the selection of feature-set for training and test data a hybrid approach of gender, recognition was used. All the numeric values have been obtained through geometrical measurements. A dataset 
having 150 male and 150 female face images, obtained from the Stanford University Medical Students database has been used for the training of the classifier. The image processing distance tool of MATLAB has been used for the calculation of facial features. The dataset of 300 images was arranged in the ".arff" file format for the training of the J48 classifier. Later 200 more test images of the same size and attributes were selected for the testing of classifier accuracy. The authors have used 200 female and 200 male grayscale face photos to test and train the classifier with $75 \%$ training and $25 \%$ testing percentage. The J48 generated a decision tree of 25 nodes for each image. The 13 leaf nodes represent the result of classification and remaining 12 branch nodes of the tree explain the difference between the two choices also known as the branching factor of the decision tree.

Nazir and Mirza, in [10] used block-based face feature selection, and face detection. The authors have used Discrete Cosine Transformation (DCT) for the detection of face parts in the image and Discrete Wavelet Transform (DWT) for the better analysis of images. The important features of the image were selected by Principal Component Analysis (PCA) instead of considering the entire input image. The best feature can be selected from extracted face features by selecting at the first left corner in a zigzag fashion. The dataset of images was divided into female and male images. The image of female and male have different face expressions so the authors have performed various experiments on Discrete Cosine Transformation and Discrete Wavelet Transformation, by using k-NN Classifier. They have used various values of ' $\mathrm{k}$ ' to analyze the difference in accuracy. The experimental results show that the proposed method performs better on LDA and Mahalanobis classifiers. The classification results on the FERET database is $95.4 \%$. The results obtained with this technique are satisfactory with the reduced number of face features by PCA.

Ergen et. al., in [11] have used 100 male and 100 female images, obtained from Face Database (FEI). Discrete Wavelet Transform (DWT) has been used as a preprocessing step. The features were extracted by applying Gray-Level CoOccurrence Matrix (GLCM). The feature group set consists of 2D wavelet transform and GLCM. They have used SVM classifier for creating two features set. The GLCM is the most famous methods for text analysis which uses Energy, Contrast, Homogeneity, and Correlation for feature extraction. For each image, seven (7) features were extracted and a feature set of $200 \times 7$ generated. Feature sets were found from 103 different types of filter in which coif1 filter has a maximum result which belongs to the Coiflet-filter family. By applying Standard Deviation, Average and Entropy along with GLCM on the original image and 7 features were calculated in all cases. With $200 \times 7$ feature set $60 \%$ result has been achieved, and with $200 \times$ 49 feature set $89 \%$ result has been achieved.

Nazir et al., in [12] proposed efficient feature selection method for gender classification. The histogram equalization has been used to overcome brightness differences in the images of male and female. The input image has been divided into the block and arranged the blocks in a zigzag order. The blocks were classified with the k-NN classifier. The features were selected with Ada Boost algorithm. The authors have used Discrete Cosine Transform (DCT) for image compression and for dimension reduction. The $\mathrm{k}-\mathrm{NN}$ has been used for gender classification with Euclidean distance to find the closest neighbors. With k-NN classifier, the testing ratio of image data set leads to $99.30 \%$ accuracy of classification.

Tin et. al., in [13] suggested a gender classification process having shape explanation, gender classification, and feature extraction steps. The extracted features of every face are represented in column matrix in a face image database to find out the normal face of male and female of the same age group of facial images. The Euclidean distance has been used to calculate the face distance of male and female images. For the dimension reduction, Principal Component Analysis (PCA) 
has been used. All face images of recognized faces are estimated on the face space to pick sets of weights which describe the role of each vector. For the unknown face of male or female a set of weights are compared to the sets of weights known as male or female faces, through which face can be recognized. The largest eigenvalue associated with eigenvector is used to reproduce the greatest change in the face image and the smallest eigenvalue associated with eigenvector is used to reproduce the small change in the face image. The weight patterns were classified to determine the age. The age of the male or female is expected based on the smallest Euclidean distance among the face class and each face space. The Nearest Neighbor has been used for the classification. They have explained a gender classification technique on the basis of 2D face images. They also applied the whole algorithm to a gender classification structure by using a web camera. The proposed method is implemented in a real-time prototype, the face recognition system for modified customer uses has produced good results.

Basha et. al., in [14] applied 1-Dimensional Continuous Wavelet Transform (CWT) method for face images, and calculated 100 wavelet measurements. The Support Vector Machine (SVM) has been trained with 400 images having values 0 and 1 for male and female images, respectively. In the testing stage 200, images were used. The SVM calculation rate is measured in terms of Mean Squared Error (MSE). The feature extraction has been carried out using Discrete Wavelet Transform, Radon Transform, and Continuous Wavelet Transform. The Wavelet coefficient is used to represent the similarity between the image and the wavelet at the specific scale. The Radon Transform calculates projections of a face imagesmatrix with identified direction or with some given angles. These frontal face images were with changes in expression, pose, and many illumination situations. The main contribution of paper was to present the effects of different face feature extraction techniques such as Discrete Wavelet Transform, Radon, and Continuous Wavelet Transform on the Support Vector machine with Kernels such as Polynomial, MLF, Linear, Quadratic, and RBF. The grey scale images and lowresolution images have been used for experimentation. The Support Vector machine performs best with Linear Kernel and CWT, which have produced only $2 \%$ error rate and high accuracy rate is $98 \%$. The error rate of the female images is high as compared to the male error rate.

Bai et. al., in [15] have used from the database of the University of Essex, UK. For classification, authors have used the Support Vector Machine (SVM). To reduce inconsistency of randomly selected images for each person, the experimental process was repeated for 10 folds. The standard deviation and normal classification accuracy for each partition were calculated. While generating Universal data, authors have investigated three different possibilities; randomly selection of one female and one male image for training, and then calculate the average. Empirical Distribution calculates the intensity values of each pixel $(\mathrm{x}, \mathrm{y})$ of the image training data, in order to evaluate the 2D distribution of all pixel intensities. The Empirical distribution is used to generate Universal samples. The authors have collected 50 images of animal faces and then manually cropped all the images which approximately covers the portion of the image same like the human faces. The images are also resized and converted to the format of human facial images. The classification accuracy improved $2 \%$ to $3 \%$ by Universal generated data through random averaging, and very small improvement approximately $1 \%$ with the empirical distribution. The use of animal faces as the Universal data reduces the classification accuracy by $2 \%$ to $5 \%$ because the animal faces are not related to the human faces so they have their own accuracy rate.

Tin, [16] method of gender classification based on face features extracted from some specific face area. Extracted face features can be represented in the form of 
column matrix. The image quality can be varied due to external conditions due to which the approximation results are unstable. The author used k-NN classification, which is one of the famous non-parametric methods. The k-Nearest Neighbor classification provides a tradeoff for the scatterings of the image training data through a priori likelihood of the involved classes. The k-NN is very robust to some face image distortions like Rotation, brightness. The dimension reduction has been carried out with Principal Component Analysis (PCA). The Pattern matching activity used to pick the right and exact feature points of the face from the face feature point, applicants. The edge existence has been measured. The correct candidates between those detected feature points can be identified by the blob detector by adjusting the complete frame model using energy reduction. This method has disadvantages like no means of robust to face direction differences and brightness abnormalities, the extraordinary cost of merging calculations, and the dependency of detection on the initial factors. The pattern matching has been carried out on the basis of subspace method to recognize correct face feature points. In this pattern matching technique, edge extraction is not essential. This is similarly robust to the noise in the image, as whole pattern information can be used. Approximately 140 face photos of various people with changed regions like European and Asian were used. The accuracy of the proposed technique with 140 images is $96.3 \%$. The optimization can reduce the processing time of the proposed method.

Khan et. al., in [17], minimized the effects of illumination of the images taken from FERET and SUMS, by histogram equalization technique. The VIOLA and JONES method have been applied for the detection of the face. Adaboost algorithm has been used for feature extraction. The background area was eliminated with Adaboost classifier. DCT and LBP has been used for the calculation of appearance and geometric information related features of the images. Experiments based on psychology have proved that features relating to five parts of an individual face (local features) such as eyes, mouth, eyebrows, chin, and nose are more informative than the information of the whole face (global features). The extraction of local features has been carried out with LBP. The optimization of extracted features has been carried out using PSO and BA. The authors have reduced the data, measurements, and tried to produce a best image feature set which represents a gender's face more accurately. Using the geometric based and appearance based face features and accuracy rate of $97.5 \%$ has been achieved with 10 geometric face features.

Wilson et. al., in [18] have used Haar Classifiers, an algorithm based on Haarlike features, developed by Viola and Jones, for the detection of face features. This process takes into consideration the nearby rectangular areas of a particular spot in the window of detection, adds up the intensity values of the pixels in these areas, and calculates the variation between these additions. On the basis of this difference, the selected parts of the image are classified. A set of two or more rectangles, adjacent to each other on selected spots, make a Haar feature. The order of such Haar-like features is termed as the classifier cascade. The transitional illustration of the image (an integral image) has been used to calculate the rectangle features. Integral images or Summed-area tables are defined as 2-D LUT (look up tables) in the shape of a matrix having the same size as that of the original image. Every element in the LUT represents a sum of pixels situated in the upper-left area of the basic image. It helps in summing up of rectangular regions in the image. The use of integral feature helps to calculate a Haar feature of any size in even time. The feature calculation is efficient and very fast. Initially, for face detection, a large number of positive and negative images are required to get the classifier trained. Then features are extracted from it. Adaboost algorithm combined with Haar-like feature algorithm has been used for the removal of irrelevant features. The training 
of the classifier requires both negative and positive images. The authors have used 1500 images, taken from the front at different angles between $0^{0}-45^{0}$, for training every facial feature. They trained three classifiers, one each for nose, mouth, and eyes to be used for detecting features of the face from images selected from the facial recognition technology database and computed the accuracy rate of the classifier. They achieved a high detection rate except for mouth. The lower half of the face image was considered for the detection of mouth. This method of decreasing area for detection of features has proved more accurate. After elimination of wrong test results around $95 \%$ percent for an eyes and nose detection has been achieved. The mouth identification has a low accuracy rate through the least size which is essential for detection.

Ravi et. al., [19] proposed a system that detects the face area using $\mathrm{YCbCr}$ skincolor from the input image to minimize the computational complexity. The $(\mathrm{Cb}, \mathrm{Cr})$ are chrominance and $(\mathrm{Y})$ is the brightness or glow of skin color in the low and high bright area of skin. The change in skin color is mostly due to the darkness or fairness of the face skin. The midpoint of the gray image has been used to measure the face boundary. The threshold of gray levels is used to measure the skin of the face. Face feature detection, contains the face feature area assessment, Mouth and Lip determination, Left Eye locating, Right Eye locating, and Nose estimation stages. The classification has been carried out with the linear Support Vector Machine (SVM) that is based on decision planes. Face image detection has been carried out on the basis of some threshold value, if the value is greater than the estimated threshold value, then the face is a MALE, otherwise, the image is a FEMALE. The threshold selection is the drawback of this paper.

\section{Critical Evaluation}

Table 1. Critical Evaluation of Techniques

\begin{tabular}{|c|c|c|c|c|}
\hline $\begin{array}{l}\text { Ref. } \\
\text { No. }\end{array}$ & Technique Used & Strengths & Limitations & Results \\
\hline$[8]$ & $\begin{array}{l}\text { - DCT based facial } \\
\text { global face } \\
\text { feature } \\
\text { extraction. } \\
\text { - Histogram } \\
\text { Equalization. } \\
\text { - Discrete Cosine } \\
\text { Transformation } \\
\text { (DCT). } \\
\text { - Local Binary } \\
\text { Pattern (LBP). }\end{array}$ & $\begin{array}{l}\text { - Robust to colors } \\
\text { effects. } \\
\text { - Highly Accurate. } \\
\text { - Takes less time to } \\
\text { detect gender } \\
\text { form image. }\end{array}$ & $\begin{array}{l}\text { - Inefficient if some } \\
\text { occlusion occurs. } \\
\text { - The performance } \\
\text { reduces for those } \\
\text { facial images } \\
\text { which contain } \\
\text { glasses. } \\
\text { - Performance } \\
\text { reduces with face } \\
\text { images which are } \\
\text { not in front sight. } \\
\text { - Angle faces } \\
\text { decrease the } \\
\text { performance. } \\
\text { - Just uses frontal } \\
\text { face image do not } \\
\text { use different } \\
\text { poses of faces. }\end{array}$ & $\begin{array}{l}\text { - It uses less than } \\
20 \text { milliseconds } \\
\text { to identify } \\
\text { Male/Female. } \\
\text { - The Accuracy of } \\
\text { the system is } \\
78.91 \% \text {. } \\
\text { - Without } \\
\text { histogram } \\
\text { equalization, the } \\
\text { accuracy is less } \\
\text { than } 70 \% \text {. } \\
\text { - By Applying } \\
\text { histogram } \\
\text { equalization, the } \\
\text { performance } \\
\text { increases up to } \\
\text { 80\%. }\end{array}$ \\
\hline [9] & $\begin{array}{l}\text { - Gender } \\
\text { classification } \\
\text { using Decision } \\
\text { Trees. } \\
\text { - J } 48 \text {. }\end{array}$ & $\begin{array}{l}\text { - Face dimension } \\
\text { reduction results } \\
\text { in the relatively } \\
\text { high accuracy } \\
\text { rate. } \\
\text { - The technique is }\end{array}$ & $\begin{array}{l}\text { - This algorithm } \\
\text { requires a data set } \\
\text { of a lot of images. } \\
\text { - J } 48 \text { performs } \\
\text { complex } \\
\text { calculations. }\end{array}$ & $\begin{array}{l}\text { - With the total } \\
\text { number of } 197 \\
\text { data items, the } \\
\text { accuracy } \\
\begin{array}{l}98.5 \% \text {. } \\
\text { - Total 3 data }\end{array}\end{array}$ \\
\hline
\end{tabular}




\begin{tabular}{|c|c|c|c|c|}
\hline & & $\begin{array}{l}\text { easy to understand } \\
\text { interpret and } \\
\text { implement. }\end{array}$ & & $\begin{array}{l}\text { items } \\
\text { incorrectly } \\
\text { classified with } \\
1.5 \% \text { Error } \\
\end{array}$ \\
\hline [10] & $\begin{array}{l}\text { - } \text { Principal } \\
\text { Component } \\
\text { Analysis (PCA). } \\
\text { - Discrete Wavelet } \\
\text { Transform } \\
\text { (DWT). } \\
\text { - Discrete Cosine } \\
\text { Transformation } \\
\text { (DCT). } \\
\text { - Support Vector } \\
\text { Machine (SVM). } \\
\text { - BPNN. } \\
\text { - NMS. } \\
\text { - NMC. } \\
\text { - LDA. }\end{array}$ & $\begin{array}{l}\text { - Elimination of the } \\
\text { redundant face } \\
\text { features. } \\
\text { - The method } \\
\text { performs well on } \\
\text { LDA and } \\
\text { Mahalanobis } \\
\text { classifiers. }\end{array}$ & $\begin{array}{l}\text { - } \text { Better } \\
\text { performance for } \\
\text { pose } \\
\text { identification, but } \\
\text { not suitable for } \\
\text { gender } \\
\text { classification. } \\
\text { - The performance } \\
\text { of the proposed } \\
\text { model is } \\
\text { marginally lower } \\
\text { on the k-NN } \\
\text { classifier. }\end{array}$ & $\begin{array}{l}\text { - The accuracy of } \\
\text { Support Vector } \\
\text { Machine (SVM) } \\
\text { is } 94.81 \% \text {. } \\
\text { - Classification } \\
\text { accuracy with } \\
\text { FERET database } \\
\text { is } 95.35 \% \text {. }\end{array}$ \\
\hline [11] & $\begin{array}{l}\text { - Gender } \\
\text { recognition using } \\
\text { Gray-Level Co- } \\
\text { Occurrence } \\
\text { Matrix (GLCM). } \\
\text { - Discrete Wavelet } \\
\text { Transform } \\
\text { (DWT). } \\
\text { - Local Binary } \\
\text { Pattern (LBP). } \\
\text { - Coif1 Filter. } \\
\end{array}$ & $\begin{array}{l}\text { - Unusual features } \\
\text { decrease the } \\
\text { similarity ratio. } \\
\text { - Robust to classify, } \\
\text { and increase } \\
\text { reliability. }\end{array}$ & $\begin{array}{l}\text { - Iterative method } \\
\text { and time } \\
\text { consuming. } \\
\text { - The result is not } \\
\text { as good with less } \\
\text { number of } \\
\text { features. }\end{array}$ & 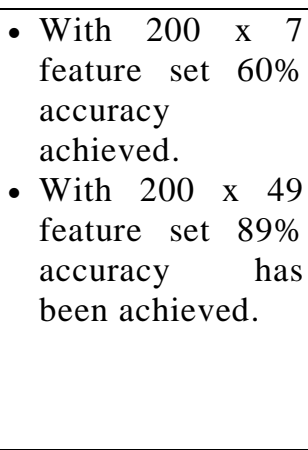 \\
\hline$[12]$ & $\begin{array}{l}\text { - DCT based facial } \\
\text { global features } \\
\text { extraction. } \\
\text { - Ada Boost } \\
\text { algorithm. } \\
\text { - Discrete Cosine } \\
\text { transform (DCT). } \\
\text { - K-Nearest } \\
\text { Neighbor (k-NN). }\end{array}$ & $\begin{array}{l}\text { - Highly accurate. } \\
\text { - Robust to varying } \\
\text { illuminations. } \\
\text { - Adaboost can get } \\
\text { the high speed of } \\
\text { computation. }\end{array}$ & $\begin{array}{l}\text { - Not suitable if } \\
\text { some obstruction } \\
\text { occurs. } \\
\text { - Adaboost suffers } \\
\text { from poor } \\
\text { classification rate. }\end{array}$ & $\begin{array}{l}\text { - Classification } \\
\text { Accuracy } \\
99.30 \% \text {. }\end{array}$ \\
\hline [13] & $\begin{array}{l}\text { - Principal } \\
\text { Component } \\
\text { Analysis (PCA). } \\
\text { - Eigen Value. } \\
\text { - k-Nearest } \\
\text { Neighbor (k-NN). }\end{array}$ & $\begin{array}{l}\text { - k-NN is very } \\
\text { compatible and } \\
\text { takes small } \\
\text { memory storage. } \\
\text { - K-NN is highly } \\
\text { robust to the } \\
\text { twisted image like } \\
\text { illumination, } \\
\text { rotation. } \\
\text { - The model has } \\
\text { small complexity } \\
\text { and is suitable for } \\
\text { real-time } \\
\text { applications. }\end{array}$ & $\begin{array}{l}\text { - The presence of } \\
\text { the person is } \\
\text { required for the } \\
\text { application. }\end{array}$ & $\begin{array}{l}\text { - Results not } \\
\text { clearly measured. }\end{array}$ \\
\hline [14] & $\begin{array}{l}\text { - Discrete Wavelet } \\
\text { Transform } \\
\text { (DWT). } \\
\text { - Radon } \\
\text { Transform. } \\
\end{array}$ & $\begin{array}{l}\text { - Fast calculation } \\
\text { and higher } \\
\text { accuracy with } \\
\text { male images. }\end{array}$ & $\begin{array}{l}\text { - The ORL face } \\
\text { database involves } \\
\text { a very small } \\
\text { number of facial } \\
\text { images of female }\end{array}$ & $\begin{array}{lrr}\text { - Only } 2 \% & \text { error } \\
\text { rate and } & 98 \% \\
\text { accuracy. } & \end{array}$ \\
\hline
\end{tabular}




\begin{tabular}{|c|c|c|c|c|}
\hline & $\begin{array}{l}\text { - Continuous } \\
\text { Wavelet } \\
\text { Transform } \\
\text { (CWT). } \\
\text { - Support Vector } \\
\text { Machine (SVM) } \\
\text { with Polynomial, } \\
\text { MLF, Linear, } \\
\text { Quadratic, and } \\
\text { RBF Kernels. }\end{array}$ & & $\begin{array}{l}\text { and does not have } \\
\text { occlusions. } \\
\text { - The error rate of } \\
\text { the female image } \\
\text { is high as } \\
\text { compared to the } \\
\text { male error rate. }\end{array}$ & \\
\hline [15] & $\begin{array}{l}\text { - } \text { Human face } \\
\text { recognition using } \\
\text { Inference by } \\
\text { Contradiction. } \\
\text { - Linear Support } \\
\text { Vector Machine } \\
\text { (SVM). }\end{array}$ & $\begin{array}{l}\text { - } \text { Performance is } \\
\text { relatively robust } \\
\text { and stable. }\end{array}$ & $\begin{array}{l}\text { - Poorly chosen } \\
\text { images like } \\
\text { animal faces can } \\
\text { degrade } \\
\text { classification } \\
\text { performance. } \\
\text { - The high } \\
\text { dimensionality of } \\
\text { data may take } \\
\text { more computation } \\
\text { time. } \\
\text { - Generalization } \\
\text { performance } \\
\text { degrades with the } \\
\text { inappropriate } \\
\text { selection of } \\
\text { Universum data. }\end{array}$ & $\begin{array}{l}\text { - } \text { The Average } \\
\text { (Standard } \\
\text { Deviation) by } \\
\text { SVM with P-1, } \\
84.4(5.5), \\
\text { - P-2, } 76.2(6.0), \\
\text { - P-3, 82.6 (3.6), } \\
\text { - P-4, 81.8 (4.1). }\end{array}$ \\
\hline [16] & $\begin{array}{l}\text { - Appearance } \\
\text { based face } \\
\text { features } \\
\text { extraction using } \\
\text { PCA. } \\
\text { - Euclidean } \\
\text { Distance. } \\
\text { - K-Nearest } \\
\text { Neighbor. }\end{array}$ & $\begin{array}{l}\text { - The suggested } \\
\text { system shows low } \\
\text { complexity which } \\
\text { can be appropriate } \\
\text { for real world } \\
\text { implementations } \\
\text { like real time face } \\
\text { animation. } \\
\text { - Their conclusions } \\
\text { are stronger in the } \\
\text { presence of noise } \\
\text { and face } \\
\text { variations. } \\
\text { The output of this } \\
\text { method is good } \\
\text { robustness \& } \\
\text { equitable accuracy } \\
\text { of face photos } \\
\text { from test images } \\
\text { set. }\end{array}$ & $\begin{array}{l}\text { - This method has } \\
\text { disadvantages like } \\
\text { no means of } \\
\text { robust to face } \\
\text { direction } \\
\text { differences and } \\
\text { brightness } \\
\text { abnormalities, the } \\
\text { extraordinary cost } \\
\text { of merging } \\
\text { calculations, and } \\
\text { the dependency of } \\
\text { detection on the } \\
\text { initial factors. } \\
\text { The processing } \\
\text { time can be } \\
\text { reduced by } \\
\text { optimization. }\end{array}$ & $\begin{array}{l}\text { - Accuracy of } \\
96.3 \% \text { with } 140 \\
\text { images. }\end{array}$ \\
\hline [17] & $\begin{array}{l}\text { - Face feature } \\
\text { extractions using } \\
\text { Local Binary } \\
\text { Patterns (LBP). } \\
\text { - Particle Swarm } \\
\text { Optimization } \\
\text { (PSO). } \\
\text { - Histogram } \\
\text { Equalization. } \\
\text { - Discrete Cosine } \\
\text { transform (DCT). }\end{array}$ & 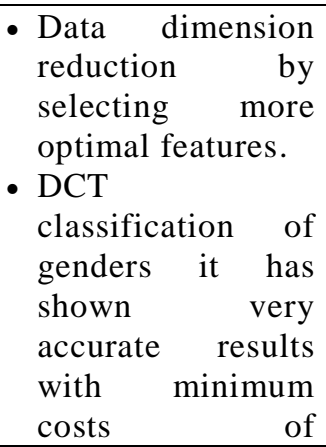 & $\begin{array}{l}\text { - PSO and BA } \\
\text { algorithm take } \\
\text { more time to } \\
\text { process the data }\end{array}$ & $\begin{array}{l}\text { - Using the } \\
\text { geometric based } \\
\text { and appearance } \\
\text { based face } \\
\text { features, } 97.5 \% \text {. } \\
\text { - The accuracy rate } \\
\text { was achieved } \\
\text { while measuring } \\
\text { just } 10 \text { geometric } \\
\text { face features. }\end{array}$ \\
\hline
\end{tabular}




\begin{tabular}{|c|c|c|c|c|}
\hline & $\begin{array}{l}\text { - Bee Algorithm. } \\
\text { - Support Vector } \\
\text { Machine (SVM). } \\
\text { - Back Propagation } \\
\text { Neural Network. } \\
\text { - K-Nearest } \\
\text { Neighbor (k-NN). }\end{array}$ & computation. & & \\
\hline [18] & $\begin{array}{l}\text { - Haar cascade } \\
\text { classifier for the } \\
\text { object detection. } \\
\text { - Adaboost } \\
\text { algorithm. }\end{array}$ & $\begin{array}{l}\text { - Regionalization } \\
\text { can increase the } \\
\text { accuracy by the } \\
\text { elimination of } \\
\text { false results. } \\
\text { - It } \\
\text { comparatively } \\
\text { better because of } \\
\text { its speedy } \\
\text { calculation. }\end{array}$ & $\begin{array}{l}\text { - Cannot provide } \\
\text { more precise } \\
\text { details of the face } \\
\text { features for the } \\
\text { recognition of } \\
\text { human emotions. } \\
\text { - The mouth } \\
\text { identification has } \\
\text { a low accuracy } \\
\text { rate through the } \\
\text { least size which is } \\
\text { essential for } \\
\text { detection. }\end{array}$ & $\begin{array}{l}\text { - After elimination } \\
\text { of wrong test } \\
\text { results around } \\
95 \% \text { percent for } \\
\text { the eyes and nose } \\
\text { detection has } \\
\text { been achieved. }\end{array}$ \\
\hline [19] & $\begin{array}{l}\text { - Support Vector } \\
\text { Machine (SVM). } \\
\text { - YCbCr skin- } \\
\text { color. }\end{array}$ & $\begin{array}{l}\text { - Much more } \\
\text { accurate and can } \\
\text { overcome various } \\
\text { face variations. }\end{array}$ & $\begin{array}{l}\text { - Choosing the } \\
\text { correct threshold } \\
\text { value for } \\
\text { classification is } \\
\text { the problematic } \\
\text { part of this } \\
\text { research. }\end{array}$ & $\begin{array}{l}\text { - Results are not } \\
\text { properly } \\
\text { presented. }\end{array}$ \\
\hline
\end{tabular}

\section{Conclusion and Future Work}

In this paper, various gender classification methods proposed by authors, using image processing techniques have been critically analyzed to point out their deficiencies. We have observed that most of the classification techniques depend on front face images and the main problem faced by them are facial variations. The variations may be the change in expression, illumination, and occlusion. The size of data, time of computation and computational complexities are also some difficulties in the efficient application of these methods in real time applications. After analyzing these techniques, it is concluded that for gender classification, computational work on pixels is more expensive than the extraction of facial features. The Support Vector Machine (SVM) has shown better accuracy rate as compared to other classifiers.

\section{References}

[1] S. A. Khan, M. Ahmed, M. Nazir and N. Riaz, "A Comparative Analysis of Gender Classification Techniques", Middle-East Journal of Scientific Research,vol. 20, no. 1, (2014), pp. 1-13.

[2] F. Wahid, M. Fayaz and A. S. Shah, "An Evaluation of Automated Tumor Detection Techniques of Brain Magnetic Resonance Imaging (MRI)", International Journal of Bio-Science and Bio-Technology, vol. 8, no. 2, (2016), pp. 265-278.

[3] M. Fayaz, A. S. Shah, F. Wahid and A. Shah, "A Robust Technique of Brain MRI Classification using Color Features and K-Nearest Neighbors Algorithm", International Journal of Signal Processing, Image Processing and Pattern Recognition, vol. 9, no. 10, (2016).

[4] A. S. Shah, M. N. A. Khan, F. Subhan, M. Fayaz and A. Shah, "An Offline Signature Verification Technique using Pixels Intensity Levels", International Journal of Signal Processing, Image Processing and Pattern Recognition, vol. 9, no. 8, (2016), pp. 205-222.

[5] A. S. Shah, M. N. A. Khan and A. Shah, "An Appraisal of Off-Line Signature Verification Techniques", International Journal of Modern Education and Computer Sciences, vol.7, no. 4, (2015), pp. 67-75.

[6] P. Rai and P. Khanna, "Gender Classification Techniques: A Review", Advances in Computer Science, Engineering \& Applications, vol. 166, (2012), pp. 51-59. 
[7] O. Singh, G. Bommagani, S. R. Ravula and V. K. Gunjan, "Pattern Based Gender Classification", International Journal of Advanced Research in Computer Science and Software Engineering, vol. 3, no. 10, (2013), pp. 888-895.

[8] E. K. Dey, M. Khan and M. H. Ali, "Computer Vision Based Gender Detection from Facial Image", International Journal of Advanced Computer Science, vol. 3, no. 8, (2013), pp. 428-433.

[9] M. N. A. Khan, S. A. Qureshi and N. Riaz, "Gender Classification with Decision Trees", International Journal of Signal Processing, Image Processing and Pattern Recognition, vol. 6, no. 1, (2013), pp. 165176.

[10] M. Nazir and A. M. Mirza, "Multi-view Gender Classification Using Hybrid Transformed Features", International Journal of Multimedia and Ubiquitous Engineering,vol. 7, no. 2, (2012), pp. 515-520.

[11] B. Ergen and S. A. But, "Gender Recognition Using Facial Images", International Conference on Agriculture and Biotechnology, vol. 60, no. 20, (2013), pp. 112-117.

[12] M. Nazir, M. Ishtiaq, A. Batool, M. A. Jaffar and A. M. Mirza, "Feature Selection for Efficient Gender Classification", 11th World Scientific and Engineering Academy and Society international conference on Fuzzy Systems, Recent Advances in Neural Networks, (2010), pp. 70-75.

[13] H. H. K. Tin, "Gender and Age Estimation Based on Facial Images", Acta Technica Napocensis Electronics and Telecommunications, vol. 52, no. 3, (2011), pp. 73-40.

[14] A. F. Basha and G. S. B. Jahangeer, "Face Gender Image Classification Using Various Wavelet Transform and Support Vector Machine with various Kernels", International Journal of Computer Science Issues, vol. 9, no. 6, (2012), pp. 150-157.

[15] X. Bai and V. Cherkassy, "Gender Classification of Human Faces Using Inference through Contradictions", International Joint Conference on Neural Networks, (2008), pp. 746-750.

[16] H. H. K. Tin, "Perceived Gender Classification from Face Images", International journal of Modern Education and Computer Science, vol. 1, (2012), pp. 12-18.

[17] S. A. Khan, M. Nazir and N. Riaz, "Optimized Features Selection for Gender Classification Using Optimization Algorithms", Turkish Journal of Electrical Engineering \& Computer Science,vol.21, (2013), pp. 1479-1494.

[18] P. I. Wilson and D. J. Fernandez, "Facial Feature Detection Using Haar Classifiers", Journal of Computer Science in Colleges, vol. 21, no. 4, (2006), pp. 127-133.

[19] S. Ravi and S. Wilson, "Face Detection with Facial Features and Gender Classification Based on Support Vector Machine", International Journal of Imaging Science and Engineering, (2010), pp. 23-28.

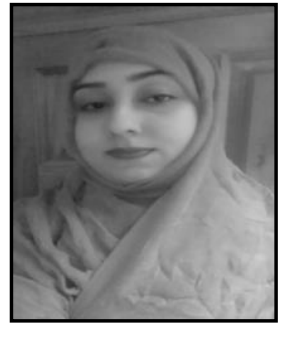

\section{Authors}

Hira Khalid Khan, has completed MS degree in Computer Science from SZABIST, Islamabad, Pakistan in 2016. She has received BS degree in Computer Science from University of Science and Technology, Bannu, Khyber Pakhtunkhwa, Pakistan in 2012. Besides her academic qualification, she has attended training of Microsoft Experts Systems, Under Directorate of Information Technology, Government of Khyber Pakhtunkhwa, Peshawar, Pakistan in 2013.

Her research area includes, Machine Learning, Artificial Intelligence, Pattern Recognition, and Digital Image Processing.

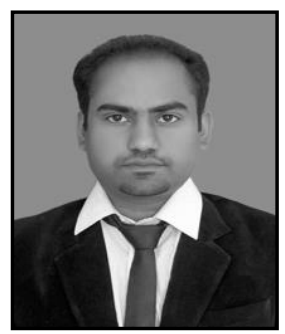

Abdul Salam Shah, is currently doing specialization in Management Information System (MIS) from Virtual University of Pakistan. He has completed MS degree in Computer Science from SZABIST, Islamabad, Pakistan in 2016. He did his BS degree in Computer Science from Isra University Hyderabad, Sindh Pakistan in 2012. In addition to his degree, he has completed short courses and diploma certificates in Databases, Machine Learning, Artificial Intelligence, Cybercrime, Cybersecurity, Networking, and Software Engineering. He has published articles in various journals of high repute. He is a young professional and he started his career in the Ministry of Planning, Development and Reforms, Islamabad Pakistan. His research area includes Machine Learning, Artificial Intelligence, Digital Image Processing and Data Mining. 
Mr. Shah has contributed in a book titled "Research Methodologies; an Islamic perspectives," International Islamic University Malaysia, November, 2015.

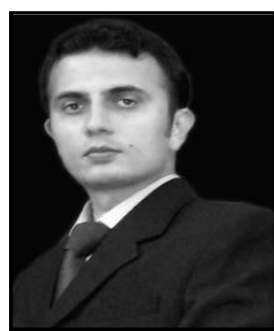

Muhammad Asim Khan, is currently working as Foreign Education Expert with Jiangxi University of Science and Technology, Ganzhou, China. His Ph.D. is under progress from International Islamic University Islamabad, Pakistan. He received MS Computer Science degree from Pir Mehar Ali Shah Arid Agriculture University Rawalpindi, Pakistan in 2012 and BS Computer Science degree from the same university in 2009. His research domain is Digital Image Processing by using Machine Learning Techniques. 
International Journal of Signal Processing, Image Processing and Pattern Recognition Vol. 9, No. 10, (2016) 